\title{
Solvent extraction in nuclear technology
}

\author{
James D. Navratil \\ Rockwell International, Rocky Flats Plant, P.0. Box 464, Golden, C0 \\ 80401 , U.S.A.
}

\begin{abstract}
Some aspects of solvent extraction chemistry in the field of nuclear technology are briefly reviewed. Applications of solvent extraction in actinide recovery and purification, radionuclide production, and reactor materials preparation are summarized. The need for new, more selective, solvent extraction reagents is presented via examples of recent work with bifunctional organophosphorus reagents applied to the removal of actinides from acidic radioactive waste solutions.
\end{abstract}

\section{INTRODUCTION}

Liquid-liquid solvent extraction technology is used in numerous industrial processes such as petroleum and petrochemical processing, organic chemical and pharmaceutical production, food and fuel industries, effluent treatment, and hydrometallurgy (ref.1). Although solvent extraction technology had its beginning more than 100 years ago, it owes a significant amount of its present prominence as a separation technique to its successful applications in the field of nuclear technology, when demands for simple separation processes for many elements, previously considered only laboratory curiosities, arose. The use of thorium, uranium, plutonium and other actinides in the nuclear energy programs and interest in metals such as hafnium-free zirconium as a reactor construction material and bismuth, gallium and indium as heat transfer media have led to the rapid development of many solvent extraction processes that display selectivity, simplicity and speed.

This paper briefly reviews the various liquid-liquid solvent extraction reagents used in several nuclear technological areas, such as purification of reactor materials, radionuclide production, and the recovery and purification of thorium, uranium, and plutonium. New reagents, especially bifunctional organophosphorus compounds for actinide removal from acidic nuclear waste solutions will be discussed with a call for better, more selective, and less expensive reagents for use in the field.

\section{APPLICATIONS}

\section{Reactor materials}

Materials employed in reactor technology along with some of the successful solvent extraction reagents used for their separation are summarized in Table 1 . Of the processes connected with the elements listed none have more challenged the nuclear chemist and engineer than those of zirconium and hafnium separation and production. Each element is always associated with the other and their chemistry is very similar. Among the extractants used for the successful separation of the two elements are tributyl phosphate (ref. 10,11), thenoyltrifluoroacetone (ref. 12) and tri-n-octylamine (ref. 13), while the addition of thiocyanate to the aqueous phase extends the range of applicable solvents to methyl-iso-butyl ketone (ref. 14), diethyl ether, n-butanol, cyclohexanone, n-butyl acetate, pentyl acetate, methyl propyl ketone, and ethyl-iso-propyl ketone (ref. 15). The solvents commonly used in industrial processes involve methyl-iso-butyl ketone and tributyl phosphate. They have the advantage of high separation factors.

\section{Radionuclide production}

A large number of radionuclides are finding ever-increasing usage in agriculture, industry, medicine and science (ref. 17), and are artificially produced by means of a nuclear reactor or a particle accelerator. When transmutation reactions are employed or interfering secondary reactions occur, chemical separations must be employed to obtain pure forms of the radionuclide. Numerous examples exist in the literature of the use of solvent extraction in the laboratory scale preparation of purified radionuclides. Some of the reagents used are briefly summarized in Table 2 . 
TABLE 1. Some solvent extractants used for producing reactor materials

\begin{tabular}{llr}
\hline $\begin{array}{l}\text { Reactor } \\
\text { Material }\end{array}$ & Solvent Extractant & Reference \\
\hline $\begin{array}{l}\text { Bismuth } \\
\text { Lead }\end{array}$ & $\begin{array}{l}\text { Diethyldithiocarbamate } \\
\text { Methyl-iso-propyl ketone }\end{array}$ & $(2)$ \\
Rare earths & Diethyldithiocarbamate-dithizone & $(3)$ \\
& Tributyl phosphate & $(4)$ \\
Tantalum/ & Butyl alcoho1/thiocyanates & $(6)$ \\
niobium & Octylarsinic acid & $(7,8)$ \\
& Tributy1 phosphate & $(9)$ \\
Zirconium/ & Tributyl phosphate & $(10,11)$ \\
hafnium & Thenoyltrifluoroacetone & $(12)$ \\
& Tri-n-octylamine & $(13)$ \\
& Methyl-iso-buty1 ketone/thiocyanate & $(14)$ \\
& Diethyl ether/thiocyanate & $(15)$ \\
& Primene JMT (a long-chain primary chain) & $(16)$
\end{tabular}

TABLE 2. Some solvent extractants used for producing radionuclides.

\begin{tabular}{|c|c|c|}
\hline Radionuclide & $\begin{array}{l}\text { Solvent } \\
\text { Extractant }\end{array}$ & rence \\
\hline Calcium-45 & $\begin{array}{l}\text { Thenoy1trifluoro- } \\
\text { acetone in } \\
\text { benzene }\end{array}$ & (18) \\
\hline \multirow[t]{2}{*}{ Cobalt -58} & $\begin{array}{l}\text { Tributy1 phosphate } \\
\text { Tributy1 phosphate }\end{array}$ & $\begin{array}{l}(19) \\
(20)\end{array}$ \\
\hline & $\begin{array}{l}\text { Methy } 1-\text { so-butyl } \\
\text { ke tone/1-pheny1- } \\
\text { 3-methy1-4-capry1- } \\
\text { pyrazolone-5 }\end{array}$ & (21) \\
\hline Copper-64 & Dithizone in $\mathrm{CCl}_{4}$ & $(22)$ \\
\hline Gold-198 & Ethy1 acetate & (23) \\
\hline Iron -59 & Isopropyl ether & (24) \\
\hline Potassium -42 & Tributy1 phosphate & (25) \\
\hline
\end{tabular}

Solvent extraction plays a key role in the Transuranium Processing Plant operated in conjunction with the High Flux Isotope Reactor at Oak Ridge National Laboratory to produce large quantities of the transuranium elements for use as heat and power sources and for distribution to researchers (ref. 26). Plutonium is recovered from dissolved irradiated targets by solvent extraction with bis-(2-ethylhexyl)phosphoric acid. The remaining transplutonium elements are then decontaminated from fission products by countercurrent solvent extraction with a high purity tertiary amine, Adogen 364, in diethylbenzene. Americium and curium are partitioned from the transcurium elements by a Lill-based anion exchange process for small-scale processes but extraction with di-(2-sthylhexyl)phosphoric acid in Amsco 125-82 diluent is preferred for large-scale production. Subsequent $\mathrm{Am}-\mathrm{Cm}$ separation and berkelium and californium isolation are achieved by precipitation, solvent extraction and chromatographic anion exhange processes respectively.

\section{Uranium recovery from ores and other sources}

The major stages in the conventional processes for the millin include leaching of uranium by acid or alkaline solutions, concentration and purification by solvent extraction or ion exchange, and precipitation. Solvent extraction has displaced many of the initial ion exchange processes for the concentration and purification of uranium from acid leaching processes. While it is primarily used with clarified acid solutions, considerable development work has been done on alkaline solutions and on solvent-in-pulp applications. The two types of solvent employed are tertiary amines (Alamine 336) and alkylphosphoric acids (di-(2-ethylhexyl)phosphoric acid) (ref. 27,28). Generally, amine solvents have superseded the alkylphosphoric acids because of their selectivity, although the latter are preferred when vanadium is present in the feed stream.

The fertilizer industry produces large quantities of wet process phosphoric acid solution containing $0.1-0.2 \mathrm{~g} / 1$ of uranium, which represent a large potential source of uranium. A two-cycle process was developed for the recovery of uranium from these phosphoric acid solutions by extraction with di-(2-ethylhexyl)phosphoric acid plus trioctylphosphine oxide in an aliphatic diluent (ref. 29). Later studies simplified the solution chemistry of the process by replacing the first extraction cycle with the commercial solvent mixture, mono and dioctylphenylphosphoric acid (octylphenylacidphosphate) (ref. 30).

\section{Spent nuclear fuel processing}

As is shown above, tributyl phosphate has found applications in many hydrometallurgical processes and is the extractant of choice in spent nuclear fuel processing. All major plants for reprocessing spent nuclear fuel employ tributyl phosphate to separate uranium and plutonium from fission products, as well as to purify the separated plutonium and uranium (ref. 31). Tributyl phosphate is also used to reprocess spent thorium containing nuclear fuels, and to separate the actinide-lanthanide fraction from reprocessing wastes.

Solvent extractants used prior to TBP included methylisobutylketone and dibutyl carbitol and many other reagents, such as alkylphosphonates, phenylphosphonates and tertiary amines, have been proposed as replacements for tributyl phosphate in the reprocessing of spent nuclear fuels (ref. 31). Thus far, the reagents investigated do not have a significant advantage over the following attractive properties of tributyl phosphate: 1) suitable extracting power, 2) good decontamination of fission products, 3) good density, viscosity, flash-point, etc., and 4) reasonable stability. 


\section{NEW SOLVENT EXTRACTANTS}

The literature abounds with articles on new extractants (re. 1,31-35). While many of the reagents are only of academic interest, several types of extractants show promise in improving actinide separation and recovery, improved recovery of uranium from its ores and other low-grade sources and promise of alternate methods for radionuclide production.

Table 3 shows some of the newer extractants that are currently being studied and their possible applications.

TABLE 3. Some new extractants and possible applications.

\begin{tabular}{lll}
\hline Extractant & Application & Reference \\
\hline Carbamoylmethylphosphonates & Actinide recovery/purification & $(32-39)$ \\
Carbamoylmethylphosphine oxides & Actinide recovery/purification & $(39)$ \\
Sulphoxides & Actinide separation & $(40,41)$ \\
Crown ethers & Pb(II), Sr(II) separation & $(42)$ \\
Arsine oxides & Actinide separation & $(35)$ \\
Macrobicycles & Na,K, Cs separation & $(43)$ \\
\hline
\end{tabular}

In the last decade there has been much interest in the potential application of the neutral bifunctional organophosphorus compounds, carbamoylmethylphosphonates(CMP) and carbamoylmethylphosphine oxides(CMPO), to remove trivalent actinides and lanthanides from strong nitric acid solutions, a property which distinguishes them from monofunctional organophosphorus compounds (ref. 33-39). The Arbuzov rearrangement

$(\mathrm{GO})_{3} \mathrm{P}+\left(\mathrm{G}^{\prime}\right){ }_{2} \mathrm{NCO}\left(\mathrm{CH}_{2}\right) \mathrm{X}--(\mathrm{GO})_{2} \mathrm{P}(\mathrm{O})\left(\mathrm{CH}_{2}\right) \mathrm{C}(\mathrm{O}) \mathrm{N}\left(\mathrm{G}^{\prime}\right)_{2}+\mathrm{GX}$

has been used to prepare (in 40 to $60 \%$ yield) carbamoylphosphonates (ref. 33). Ki:m et al. (ref. 44) have discovered a phase transfer-catalyzed Michaelis-Becker reaction which is not plagued by the side reactions typical of conventional Arbuzov synthesis which seriously limit yields and purities of crude products.

Two general methods for preparing phosphine oxides have been reported (ref. 45):

$$
\begin{aligned}
& 2\left(\mathrm{G}_{2}\right) \mathrm{P}(\mathrm{O}) \mathrm{MgX}+\mathrm{X}\left(\mathrm{CH}_{2}\right)_{\mathrm{n}} \mathrm{X} \rightarrow(\mathrm{G})_{2} \mathrm{P}(\mathrm{O})\left(\mathrm{CH}_{2}\right)_{\mathrm{n}}(\mathrm{P}) \mathrm{O}(\mathrm{G})_{2}+2 \mathrm{MgX}_{2} \\
& 2 \mathrm{G}_{2} \mathrm{POCl}+\left(\mathrm{CH}_{2}\right)_{\mathrm{n} \geq 4}(\mathrm{MgX})_{2} \rightarrow(G)_{2} \mathrm{P}(\mathrm{O})\left(\mathrm{CH}_{2}\right)_{\mathrm{n} \geq 4}(\mathrm{O}) \mathrm{P}(\mathrm{G})_{2}+\mathrm{MgCl}_{2}+\mathrm{MgX}_{2}
\end{aligned}
$$

Compounds which are solids at room temperature, such as phosphine oxides, can be readily purified by repeated recrystallizations, whereas with crude carbamoylphosphonates several methods have been used (ref. 33). Vacuum distillation ( 0.001 torr, 110 degrees $\mathrm{C}$ ), high pressure liquid chromatography, and salt precipitation methods have been very successful in purifying carbamoylmethylphosphonates, with the latter method being preferred.

Most recently, Horwitz and coworkers (ref. 39) have evaluated a number of neutral bifunctional organophosphorus extractants containing the $\mathrm{P}(0)\left(\mathrm{CH}_{2}\right)_{n} \mathrm{C}(\mathrm{O}) \mathrm{N}$ moiety for their ability to extract americium from nitric acid and their selectivity for americium over iron and selected fission products. Compounds containing alkoxy, alkyl, and aryl substituents were evaluated. The most efficient and selective americium extractants contain a single carbon bridging group, one or two phenyl groups attached to the phosphorus atom and isobutyl groups attached to the amide nitrogen. Fig. 1 summarizes the properties affected by substituents on the carbamoyl-phosphoryl moiety.

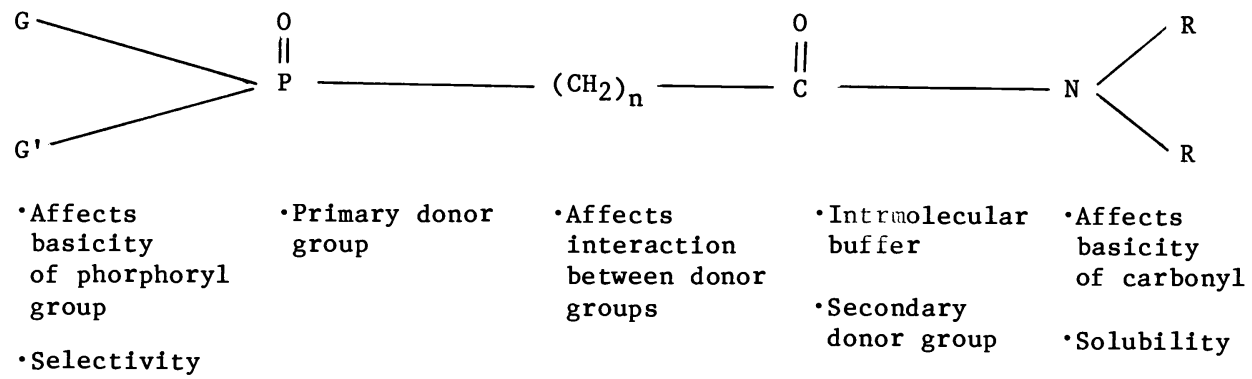

- Solubility

Fig. 1. Effect of substituents on the properties of the carbamoylphosphoryl moiety. 


\section{CONCLUSION}

Solvent extraction technology plays a vital role in actinide recovery and purification, radionuclide production, the preparation of reactor materials, and other aspects of the nuclear field. There are challenging research areas for the separations chemist and synthetic organic chemist to wotk together to improve solvent extraction processes and develop energy saving process technology. One major area alluded to in this paper is through the preparation and testing of new reagents which have a far greater selectivity for the solute species, better overall recovery, improved physical properties, less toxicity, and lower costs.

\section{REFERENCES}

1. T. C. Lo, M. H. I. Baird, and C. Hanson, Handbook of Solvent Extraction, Wiley, New York (1983).

2. K. L. Cheng, R. H. Bray, and S. W. Melsted, Anal. Chem., 27, 24 (1955).

3. P. W. West, and J. K. Car1ton, Anal. Chim. Acta, 6, 406 (1952).

4. A. D. Maynes, and W. A. E. McBryde, Anal. Chem., 30, 1139 (1958).

5. B. Weaver, F. A. Kappelman, and A. C. Topp, J. Am. Chem. Soc., 75, 3943 (1953).

6. D. B. Appleton, and P. W. Selwood, J. Am. Chem. Soc., 63, 2029 (1941).

7. C. W. C. Milner, G. A. Barnett, and A. A. Smales, Analyst, 80, 380 (1955).

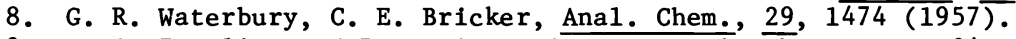

9. K. G. Irgolic, and R. J. G. Dominguez, Anal. Chim. Acta, 84, 119 (1977).

10. F. Hudswe11, and J. M. Hutcheon, Chim. Ind. (Milan), 76, $\overline{491}$ (1956).

11. P. P. Cox, H. C. Peterson, and G. H. Beyer, Ind. Eng. Chem., 50, 141 (1958).

12. B. G. Shultz, and E. M. Larson, J. Am. Chem. Soc., $72,3610(\overline{1950})$.

13. E. Cerrai, and C. Testa, Energ. Nuc1. (Milan), $6,7 \overline{07}$ (1959).

14. H. Greenberg, and R. A. Fooj, U. S. Patent 3069232, 14 July (1959).

15. W. Fischer, H. Pohlmann, and K. Adam, Anc: :. Chem., 328, 252 (1964).

16. I. S. E1-Yamani, M. Y. Farah, and F. A. A. E1-Aleim, Talanta, 25, 523 (1978).

17. J. N. Gregory, The World of Radioisotopes, Angus and Robertson, Sydney (1966).

18. A. F. Rupp, Peacefu1 Uses of Atomic Energy (Proc. Conf. Geneva, 1955), 14, 68, UN, New York (1956).

19. V. I. Levin, et a1., Radiokhimiya, $\underline{5}, 37$ (1963).

20. V. I. Levin, M. M. Golutvina, and E. A. Tikhominova, Radiokhimiya, 2, 596 (1960).

21. M. Y. Mirza, Int. J. App1. Radiat. Isot., 18, 849 (1967).

22. H. R. Haymond, et a1., J. Chem. Phys., 18, 901 (1950).

23. J. F. Emery, and G. W. Liddicotte, Rep. NAS-NS-3036, 24 (1961).

24. A. C. Wah1, J Chem. Phys., 21, 182 (1953).

25. L. N. Kurchatova, et a1., Radiokhimiya, $\frac{5}{2}, 37$ (1963).

26. Oak Ridge National Laboratory, Chemical Technology Division Annual Progress Rep. ORNL 4422, 154-58 (1969).

27. C. A. Blake, K. B. Brown, and C. F. Coleman, Rep. ORNL-1903 (1955).

28. K. B. Brown, C. F. Coleman, D. J. Crouse, J. D. Denis, and J. G. Moore, Rep. ORNL-1734 (1954).

29. F. J. Hurst, D. J. Crouse, K. B. Brown, Ind. Eng. Chem., Process Des. Dev., 11, 122 (1972).

30. F. J. Hurst, and D. J. Crouse, Ind. Eng. Chem. Process Des. Dev, 13, 286 (1974).

31. W. W. Schulz and J. D. Navratil, Science and Technology of Tributy1 Phosphate, Vo1. 1, CRC Press, Boca Raton, FL. (1984).

32. R. R. Shoun, and W. J. McDowe11, Actinide Separations (J. D. Navrati1, W. W. Schu1z, Eds.), American Chemical Society, Washington, D. C. (1980).

33. W. W. Schulz, and J. D. Navratil, Recent Developments in Separation Science, (L, N.N.L., Ed.), CRC Press, Boca Raton, Florida (1981).

34. W. W. Schulz and J. D. Navratil, Sep. Sci. Techno., 19, 927 (1984).

35. A. M. Rozen, Radiokhimiya, 26, 346 (1984).

36. J. D. Knighton, P. G. Hagan, J. D. Navrati1, C. C. Perry, G. H. Thompson, Transplutonium Elements-Production and Recovery, (J. D. Navratil, W. W. Schulz, Eds.), American Chemical Society, Washington, D. C. (1981).

37. W. W. Schulz, and L. D. McIsaac, Rep. ARH-SA-263 (1977).

38. L. D. McIsaac, J. D. Baker, J. F. Krupa, R. E. Lapointe, D. H. Merkrantz, and N. C. Schroeder, Rep. ICP-1180 (1979).

39. E. P. Horwitz, K. A. Martin, H. Diamond and L. Kaplan, Solv. Extr. Ion Exch., 4 in press (1986).

40. Yu. E. Nikitin, Yu. I. Murinov, A. M. Rozen, Russ. Chem. Rev., 45, 1155 (1976).

41. V. V. Ramakrishna, S. K. Pati1, L. Krishna Reddy, A. S. Reddy, J. Inorg, Nuc1. Chem., 41, 108-13 (1979).

42. T. Sekine, K. Shioda, and Y. Hasegowa, J. Inorg. Nuc1. Chem., 41, 571 (1979).

43. M. Timenez-Reyes, A. G. Maddock, G. Duplatz, and J. J. Schleiffer, J. Inorg. Nuc1. Chem., 41, 1365 (1979).

44. K. M. Kim, N. V. Nguyen, and D. J. Cross, J. Org. Chem., 46, 5188 (1981).

45. K. Moedritzer and R. R. Irani, J. Inorg. Nucl. Chem., 22, 297 (1961). 